DOI https://doi.org/10.17308/vsu.proc.law.2021.2/3401

\title{
ДЕЯТЕЛЬНОСТЬ СОТРУДНИКОВ ИСПРАВИТЕЛЬНЫХ УЧРЕЖДЕНИЙ И СЛЕДСТВЕННЫХ ИЗОЛЯТОРОВ ПО РАССМОТРЕНИЮ СООБЩЕНИЙ О ПЕНИТЕНЦИАРНЫХ ПРЕСТУПЛЕНИЯХ: ПРОБЛЕМЫ, ТЕНДЕНЦИИ, ПЕРСПЕКТИВЫ
}

\author{
А. С. Шаталов, А. В. Акчурин \\ Академия ФСИН России
}

Поступила в редакцию 9 апреля 2021 г.

\begin{abstract}
Аннотация: рассматриваются актуальные проблелы вылвления, раскрытия и расследования преступлений, совершаельх осужденныли, обвиняельли, подозреваелыли в период их нахождения в исправительных учреждениях и следственньх изоляторах. Опираясь на данные офиииальной уголовной статистики и собственные теоретические обобщения, авторы показывают, что непрекращающееся ежегодное увеличение числа пенитенииарных преступлений, высокая вероятность стать очередной жертвой пенитенииарной преступности для законопослушных осужденных порождает необходимость совершенствования практики реагирования на них через улучшение состояния действующего норлативно-правового регулирования, а также внедрения достижений науки и техники в повседневную деятельность сотрудников органов и учреждений, исполняющих наказания.

Ключевые слова: исправительное учреждение, латентная преступность, осужденный, следственный изолятор, сообщение о преступлении, предварительное расследование, пенитенииарнье преступления.
\end{abstract}

\begin{abstract}
: the article deals with the actual problems of detection, disclosure and investigation of crimes committed by convicted persons, accused persons, suspects during their stay in correctional institutions and pre-trial detention centers. Based on the data of official criminal statistics and their own theoretical generalizations, they show how the continuous annual increase in the total number of penitentiary crimes, the high probability of becoming another victim of penitentiary crime for law-abiding convicts, naturally creates the need to improve the practice of responding to them, through improving the current state of legal regulation, as well as the introduction of science and technology in the daily activities of employees of bodies and institutions that execute sentences.
\end{abstract}

Key words: correctional institution, latent crime, convicted person, pre-trial detention facility, crime report, preliminary investigation, penitentiary crimes.

На Федеральную службу исполнения наказаний (далее - ФСИН России) возложена обязанность по обеспечению правопорядка в следственных изоляторах и в учреждениях, исполняющих уголовные наказания в виде лишения свободы ${ }^{1}$. Через ее выполнение обеспечивается

${ }^{1}$ Вопросы Федеральной службы исполнения наказаний : указ Президента РФ от 13 октября 2004 г. № 1314 // Рос. газета. 2004. 19 окт. Федеральный вып. № 3607.

(C) Шаталов А. С., Акчурин А. В., 2021 


\section{Вестник ВГУ. Серия: Право}

безопасность находящихся на их территории осужденных, лиц, содержащихся под стражей, а также работников уголовно-исполнительной системы, граждан и должностных лиц. Несмотря на предпринимаемые усилия по обеспечению законности, в местах принудительного содержания практически постоянно совершаются различные правонарушения. Особое беспокойство вызывают новые преступления со стороны некоторых представителей спецконтингента. Они отличаются не только большой распространенностью, но и низкой раскрываемостью, являющейся последствием недостатков и упущений сотрудников правоохранительных органов, привлеченных к их предварительному расследованию. Негативное влияние на качество их процессуальной деятельности оказывает и то обстоятельство, что администрация каждого пенитенциарного учреждения более всего опасается количественного роста уголовно наказуемых действий на подконтрольной ей территории. В результате в официальной уголовной статистике фригурируют лишь те преступления осужденных и лиц, находящихся под стражей, которые невозможно или нецелесообразно укрывать. Соответственно, латентность пенитенциарных преступлений была и остается довольно высокой, а сама процессуальная деятельность, осуществляемая в связи с их совершением, весьма далекой от идеала.

Анализ официальных статистических данных ФСИН России о состоянии преступности среди лиц, содержащихся в следственных изоляторах и исправительных учреждениях, позволяет разделить все совершенные ими преступления на определенные группы. В их числе:

- незаконный оборот наркотических средств и психотропных веществ $(26 \%)$

- дезорганизация деятельности учреждений, обеспечивающих изоляцию от общества (21\%);

- побеги из мест лишения свободы (13\%);

- насильственные преступления (12\%);

- иные преступления (в том числе мошенничество, дача взятки и др.) $-28 \%$.

Наметился также рост общего числа преступлений, совершаемых осужденными в исправительных колониях уголовно-исполнительной системы, а именно: с 851 в 2016 г. до 1011 в 2020 г., т. е. на 19 \%². В следственных изоляторах и тюрымах их рост оказался еще более внушительным: с 100 в 2016 г. до 173 в 2020 г., т. е. на $73 \%{ }^{3}$. В таких условиях возрастает потребность в своевременном и профессиональном реагировании сотрудников исправительных учреждений и следственных изоляторов на различные вызовы, напрямую связанные с новыми нарушениями уголов-

${ }^{2}$ Характеристика лиц, содержащихся в исправительных колониях для взрослых. URL: https://fsin.gov.ru/structure/inspector/iao/statistika/Xar-ka\%20lic\%20sodergahixsya $\% 20 \mathrm{v} \% 20 \mathrm{IK} /$

${ }^{3}$ Характеристика лиц, содержащихся в следственных изоляторах и тюрьмах. URL: https://fin.gov.ru/structure/inspector/iao/statistika/Xar-ka\%20v\%20CIZOiT/ 
но-правовых запретов со стороны осужденных, а также заключенных под стражу обвиняемых и подозреваемых.

Основным предназначением органов и учреждений уголовно-исполнительной системы, фрункционирующих на территории Российской Федерации, является исполнение уголовных наказаний в отношении осужденных и содержание под стражей лиц, обвиняемых либо подозреваемых в совершении преступлений. Как уже отмечалось, изоляция от общества не всегда влечет за собой отказ от совершения ими новых противоправных действий. Об этом, в частности, свидетельствует тот фракт, что несмотря на заметное сокращение контингента лиц, находящихся в пенитенциарных учреждениях, число совершенных и готовящихся ими преступлений постоянно растет. Проблема заключается в том, что в действительности их совершается намного больше, чем учитывается в официальной уголовной статистике ${ }^{4}$. Насколько именно - точно не знает никто. Но на этот счет есть множество весьма разнообразных экспертных мнений. Не останавливаясь на их рассмотрении, отметим, что в научных публикациях встречаются не лишенные оснований утверждения о том, что реальное число таких преступлений, превышает официальное в десятки раз ${ }^{5}$. С данной точкой зрения у нас нет оснований не соглашаться, поскольку латентная составляющая пенитенциарной преступности очень велика и нуждается не только в более точных экспертных оценках, но и в обстоятельном научном анализе. Постараемся коротко его изложить.

Латентная преступность в классической интерпретации может иметь естественную или искусственную природу. Первая ее разновидность объединяет все преступления, о которых правоохранительные органы по независящим от них причинам не были осведомлены. Ее существование криминологи считают объективным явлением и объясняют недоверием пострадавших от преступных действий лиц к государственной правоохранительной системе ${ }^{6}$. Искусственная латентная преступность, напротив, формируется за счет преступлений, о которых государственным правоохранительным органам было известно, однако в силу каких-то причин их либо не зарегистрировали, либо должным образом не расследовали ${ }^{7}$. По нашему глубокому убеждению, применительно к пенитенциарной пре-

${ }^{4}$ См.: Хохрин C. A. Некоторые аспекты латентностной характеристики пенитенциарной преступности // Вестник Тверского гос. ун-та. Серия: Право. 2017. № 3. C. 61-74.

${ }^{5}$ См., например: Иншаков С. M. Теоретические основы исследования и анализа латентной преступности. М., 2011.

${ }^{6}$ См., например: Панасенко E. K. Латентность пенитенциарной преступности как угроза криминологической безопасности УИС // Закон и право. 2006. № 10. C. 61-63 ; Ваганов А. Б. Криминологическая характеристика пенитенциарной преступности и ее профилактика : автореф. дис. ... канд. юрид. наук. Челябинск, 2012.

${ }^{7}$ См., например: Гилинский Я. И., Акутаев Р. М. Криминология. Теория, история, эмпирическая база, социальный контроль. 2-е изд., перераб. и доп. СПб., 2009. 


\section{Вестник ВГУ. Серия: Право}

ступности можно констатировать присутствие в ее структуре френомена смешанной латентности, имеющей двойственную природу, т. е. и естественную, и искусственную одновременно. Причем без каких-либо отчетливо просматриваемых пограничных состояний, поскольку она представляет собой не что иное, как совокупность преступлений, совершенных или подготавливаемых в условиях строгой изоляции, но по разным причинам не повлекших за собой процедуры уголовного преследования причастных к их совершению лиц во время их пребывания в учреждениях уголовно-исполнительной системы.

Полный и объективный учет сообщений о преступлениях является одной из важнейших задач, стоящих перед органами и учреждениями ФСИН России, поскольку без их своевременной регистрации невозможно осуществлять полноценную борьбу с пенитенциарной преступностью в целом. Укрытие персоналом исправительных учреждений и следственных изоляторов преступлений от регистрации можно считать одним из ключевых компонентов искусственной латентности, поскольку оно представляет собой умышленное совершение должностными лицами преступных действий, выражающихся в основном в форме незаконного уклонения от написания и регистрации соответствующего рапорта либо совершения иных преступных действий (бездействия), направленных на искажение статистической отчетности в целях создания видимости благополучной обстановки в конкретном исправительном учреждении или следственном изоляторе.

Результаты проведенных исследований показали, что в органах и учреждениях ФСИН России пока не создана четкая и единообразная система ведения объективной уголовной статистики, которая могла бы, с одной стороны, повысить эффективность ведомственного контроля над пенитенциарной преступностью, а с другой - обеспечила бы осужден이 ным, обвиняемым и подозреваемым гарантированный Конституцией РФ доступ к правосудию, которому должны непременно предшествовать регистрация сообщений о преступлениях и их предварительная проверка. Анализ объективных и субъективных обстоятельств, которые приводят к искажению статистических показателей о состоянии пенитенциарной преступности, позволил выявить ряд причин избирательной подачи сообщений о тех или иных ее проявлениях и отказов от их регистрации. Эти причины весьма многочисленны и разнообразны по своей сути. Условно их можно разделить на исторические, организационные, кадровые, правовые и социально-психологические.

Их историческая подоплека видится в том, что еще с советских времен перед правоохранительными органами государства ставилась задача по искоренению преступности ${ }^{8}$. Не имея объективной возможности решить ее на территории отдельно взятого учреждения, сотрудники уголовно-исполнительной системы научились искусственно улучшать результаты

${ }^{8}$ См., например: Крылиов A. А. Уголовно-процессуальная деятельность органов и учреждений уголовно-исполнительной системы России. М., 2017. 
своей профессиональной деятельности через формирование «позитивных» (в глазах вышестоящих руководителей) статистических показателей. Всё это практикуется и сейчас. Хочется верить, что в меньших масштабах.

Организационные причины, связываются нами с особенностями учитывания пенитенциарных преступлений (уже упоминалось, что, как правило, регистрируются только те из них, которые укрыть невозможно), а также просчетами в организации ведомственного контроля и прокурорского надзора за соблюдением учетно-регистрационной дисциплины на местах. Уместно напомнить, что ежегодно прокурорами ставится на учет около 150 тыс. неучтенных в официальной уголовной статистике преступных деяний 9 . Обращает на себя внимание тот фракт, что абсолютное большинство из них устанавливается в ходе прокурорских проверок отказных материалов и материалов уголовных дел о событиях, расследование которых начинали органы дознания.

Наличие кадровых причин объясняется практически полным отсутствием у должностных лиц, проходящих службу в уголовно-исполнительной системе, необходимых умений и навыков по рассмотрению в процессуальном порядке сообщений о преступлениях и их всесторонней проверке. Правовые причины объясняются, в свою очередь, серьезными недостатками нормативно-правового обеспечения этой второстепенной для системы исполнения наказаний работы на ведомственном уровне. Так, пока не издана внятная и подробная инструкция об участии в процессуальной деятельности по расследованию пенитенциарных преступлений, должностных лиц органов и учреждений ФСИН России; недостаточно четко урегулирован порядок осуществления ими учетно-регистрационной работы и др.

Существование социально-психологических причин обусловлено тотальным недоверием осужденных, обвиняемых, подозреваемых не только к персоналу пенитенциарных учреждений, но и к другим сотрудникам правоохранительных органов; боязнью мести или неуважения со стороны других осужденных; нежеланием широкой огласки фокта совершения противоправного деяния (например, оскорблений, вымогательств, побоев, насильственных действий сексуального характера и др.) и неприятием правомерного реагирования на него; низким уровнем повседневной правовой помощи и психологической поддержки, оказываемой осужденным в органах и учреждениях ФСИН России; их недостаточной защищенностью от неправомерных действий со стороны отдельных представителей администрации исправительного учреждения; беспокойством за собственную безопасность. К этому можно добавить правовую индифферентность и межличностную отчужденность, ставшие неотьемлемыми чертами образа жизни лиц, находящихся в местах лишения свободы.

Переходя к рассмотрению способов укрытия преступлений от учета, следует отметить, что они достаточно многообразны и могут быть охарактеризованы как типичные или наиболее распространенные и специ-

${ }^{9}$ Состояние законности и правопорядка в Российской Федерации и работа органов прокуратуры : информационно-аналитическая записка. М., 2015. С. 84. 


\section{Вестник ВГУ. Серия: Право}

фические, т. е. используемые в каком-то конкретном случае незаконного реагирования сотрудников органов и учреждений ФСИН России на ставшие им известными факты совершения преступлений. Применительно к стадии возбуждения уголовного дела, они, как правило, реализуются на этапе приема сообщений о преступлениях, на этапе их регистрации и проверки. Представляется, что наибольшее практическое значение для выявления и предотвращения таких негативных фактов имеет классификация способов укрывательства в зависимости от применяемых приемов манипулирования информацией о совершенных и готовящихся преступлениях. По этому основанию можно, в частности, выделить следующие способы, при которых сообщения о пенитенциарных преступлениях не получают должного отражения в документации исправительного учреждения или следственного изолятора:

- уклонение сотрудника исправительного учреждения или следственного изолятора от составления рапорта о действиях осужденных, обвиняемых, подозреваемых, подпадающих под признаки преступления, предусмотренного Особенной частью УК РФ;

- сокрытие информации, полученной сотрудником исправительного учреждения или следственного изолятора при осуществлении оперативно-розыскной деятельности, о действиях (бездействии) осужденных, обвиняемых, подозреваемых, подпадающих под признаки преступления, предусмотренного Особенной частью УК РФ;

- отказ в приеме сообщения о преступлении, с которым обратился осужденный, обвиняемый, подозреваемый;

- невыполнение требований ведомственных нормативных правовых актов о регистрации сообщения о преступлении;

- регистрация сообщения о преступлении с нарушением требований $\sim$ ведомственных нормативных правовых актов;

- заведомо необоснованное направление поступившего сообщения о преступлении по подследственности в другой правоохранительный орган;

- умышленное искажение результатов проверочных действий с целью искусственного придания законности итоговому решению по сообщению о преступлении;

216 - одновременное рассмотрение нескольких самостоятельных сообщений о преступлениях в рамках одного и того же материала проверки или возбужденного уголовного дела.

По нашим оценкам, наиболее распространенными в органах и учреждениях уголовно-исполнительной системы способами укрытия преступлений от учета являются отказы в приеме сообений о преступлениях, с которыми обращались осужденные, обвиняемые, подозреваемые, и умышленное невыполнение требований ведомственных нормативных правовых актов о порядке регистрации сообщений такого рода. Полагаем, что их «популярность» обусловлена:

- недостатком умений и навыков по применению норм материального и процессуального права у должностных лиц органов и учреждений уголовно-исполнительной системы; 
- несоблюдением сроков, предусмотренных УПК РФ для проверки поступивших сообщений о преступлениях;

- отсутствием в произведенных проверках полноты, объективности и всесторонности;

- ошибочными квалификациями действий заподозренных лиц;

- невозможностью установления всех обстоятельств произошедшего и др.

Таким образом, под укрытием пенитенциарных преступлений от учета следует понимать систему умышленных действий, нацеленных на подготовку, совершение и сокрытие должностными лицами органов и учреждений уголовно-исполнительной системы имевших место нарушений учетно-регистрационной дисциплины и предусмотренного УПК РФ порядка рассмотрения сообщений о совершенных и готовящихся преступлениях.

Анализ следственной и судебной практики, материалов проверок сообщений о совершенных в исправительных учреждениях и следственных изоляторах преступлениях, интервьюирование сотрудников, участвовавших в таких проверках, позволяет утверждать, что основной проблемой в осуществлении доказывания противоправной деятельности осужденных являются сложности с осуществлением проверочных мероприятий и процессуальных действий при ее расследовании. Довольно часто их производство основывается на том опыте, который имеется у должностных лиц в том или ином пенитенциарном учреждении, и зависит от позиции руководителей местных правоохранительных органов. Такое положение дел приводит к тому, что документирование противоправной деятельности осужденных происходит несвоевременно и поверхностно ${ }^{10}$, что ведет к утрате следов преступления и, соответственно, снижает возможность формирования качественной доказательственной базы, позволяющей обеспечить неотвратимость привлечения к уголовной ответственности виновных ${ }^{11}$.

Понятно, что деятельность, связанная с раскрытием и расследованием преступлений осужденных, обвиняемых, подозреваемых для сотрудников исправительных учреждений и следственных изоляторов не является основной. Специально подготовленные для осуществления такой деятельности должностные лица в их штате, как правило, отсутствуют. Положение усугубляется тем, что начальники органов и учреждений уголовно-исполнительной системы весьма неохотно принимают на себя полномочия органа дознания, предусмотренные ст. 40 УПК РФ. Принимая во внимание данные обстоятельства, считаем уместным предложить новый вариант повышения результативности предварительных

${ }^{10}$ См.: Антипов А. Ю. Использование доказательств по уголовным делам // Организационно-правовое обеспечение деятельности учреждений и органов ФСИН России : проблемы и перспективы развития в условиях реформирования уголовно-исполнительной системы. Рязань, 2015. С. 18-21.

${ }^{11}$ См.: Качалов В. И. Теоретические основы доказывания при исполнении итоговых судебных решений в уголовном процессе России. М., 2017. 


\section{Вестник ВГУ. Серия: Право}

проверок, проводимых по сообщениям о преступлениях должностными лицами исправительных учреждений и следственных изоляторов, общий смысл которого сводится к применению следующего криминалистического алгоритма, специально разработанного нами для повышения эфрфективности данной деятельности:

1) сотрудник исправительного учреждения или следственного изолятора, осужденный, подозреваемый, обвиняемый либо иное лицо, которому стало известно о событии преступления, сообщает об этом дежурному по учреждению и составляет письменный рапорт или заявление;

2) оперативный дежурный по исправительному учреждению или следственному изолятору в связи с этим предпринимает следующие действия:

- по проверке достоверности поступившей информации о преступлении с привлечением оперативных сотрудников;

- по сохранению следов преступления;

- по изоляции потерпевшего и подозреваемого от основной массы осужденных, обвиняемых, подозреваемых;

- по оказанию медицинской помощи пострадавшим (при необходимости);

3) оперативный сотрудник исправительного учреждения или следственного изолятора, получивший информацию о преступлении от оперативного дежурного, комплексно производит следующие действия:

- осуществляет проверку поступившей информащии о преступлении;

- устанавливает очевидцев имевшего место события и опрашивает их;

- просматривает все последние записи, сделанные посредством видеокамер и видеорегистраторов;

- составляет рапорт об обнаружении признаков преступления и пе$\sim$ редает его начальнику исправительного учреждения или следственного 으 изолятора;

- получает от начальника исправительного учреждения или следственного изолятора поручение о проведении проверки в предусмотренном законом порядке;

- получает письменные объяснения от очевидцев происшествия, а в случае отказа от дачи объяснения составляет соответствующий акт;

- устанавливает наличие архивных видеоматериалов, имеющих непосредственное отношение к проверяемому событию, обеспечивает их сохранность и приобщение к материалам проверки;

- осматривает место происшествия и составляет протокол этого следственного действия;

- истребует документы, имеющие отношение к исследуемому событию (в том числе копии приказов о назначении на должность, служебных удостоверений, должностных инструкций, выписки из личных дел осужденных, характеристики, справки о поощрениях и взысканиях осужденного и т. д.);

- не позднее трех суток с момента регистрации сообщения о преступлении представляет начальнику исправительного учреждения или 
следственного изолятора для утверждения постановления о передаче сообщения о преступлении по подследственности и сопроводительного письма на имя руководителя соответствующего органа дознания или предварительного следствия с описью материалов проверки;

- в течение 24 часов после подписания данных документов направляет их адресату, уведомляет о принятом решении заявителя;

- копию материалов проверки размещает в номенклатурном деле исправительного учреждения или следственного изолятора;

4) при осуществлении предварительного расследования оперативные сотрудники:

- входят в состав следственной группы;

- поддерживают взаимодействие со следователем или дознавателем, выполняют их отдельные поручения;

- осуществляют оперативное сопровождение предварительного расследования до принятия итогового решения по уголовному делу.

Таким образом, сведения, изложенные и систематизированные в данной статье, несомненно, подтверждают правильность позиции, доминирующей среди руководства службы и российских ученых-пенитенциаристов относительно того, что обеспечение правопорядка и законности в местах принудительного содержания является одной из наиболее сложных задач, решаемых ФСИН России ${ }^{12}$. Это действительно так, поскольку меры по предотвращению, выявлению, раскрытию и расследованию преступлений, совершаемых осужденными, обвиняемыми, подозреваемыми в период их нахождения в исправительных учреждениях и следственных изоляторах, не могут быть результативными лишь на уровне какого-то одного отдельно взятого ведомства. Более того, непрекращающееся ежегодное увеличение численности пенитенциарных преступлений, высокая вероятность стать очередной жертвой пенитенциарной преступности для законопослушных осужденных закономерно порождают необходимость совершенствования практики реагирования на них через улучшение состояния действующего нормативно-правового регулирования, а также повсеместного внедрения достижений науки и техники в повседневную деятельность сотрудников органов и учреждений, исполняющих наказания.

Рассматривая перспективы улучшения качества процессуальной деятельности по проверке сообщений о подготовке и совершении пенитенциарных преступлений, приходим к выводу, что необходима комплексная разработка перспективной модели ее нормативно-правового регулирования, которая не ограничивалась бы расширенной интерпретацией тех или иных статей действующего уголовно-процессуального закона, а охватывала бы все практические нюансы этой деятельности, научные рекомендации по ее осуществлению с учетом специфики производства каждого процессуального действия. Искусственное отстранение сотрудников органов и учреждений уголовно-исполнительной системы от участия в процессуальной деятельности и сохранение для них нынешнего фрормата

${ }^{12}$ См.: Калашников А. Право сидящего // Рос. газета. 2019. 4 дек. 


\section{Вестник ВГУ. Серия: Право}

регистрационной дисциплины ни к чему хорошему не приведет. В лучшем случае ухудшится контроль над оперативной обстановкой в местах лишения свободы, а в худшем - число пенитенциарных преступлений резко возрастет и, следовательно, понизится эфрфективность деятельности всей пенитенциарной системы. Очевидно, что этого допустить нельзя...

\section{Библиографический список}

Антипов А. Ю. Использование доказательств по уголовным делам // Организационно-правовое обеспечение деятельности учреждений и органов ФСИН России : проблемы и перспективы развития в условиях редрормирования уголовно-исполнительной системы. Рязань, 2015. С. 18-21.

Ваганов А. Б. Криминологическая характеристика пенитенциарной преступности и ее профилактика : автореф. дис. ...канд. юрид. наук. Челябинск, 2012. 30 c.

Гилинский Я. И., Акутаев Р. М. Криминология. Теория, история, эмпирическая база, социальный контроль. 2-е изд., перераб. и доп. СПб. : Юридический центр Пресс, 2009. 504 с.

Иншаков С. М. Теоретические основы исследования и анализа латентной преступности. М. : Юнити-Дана, 2011. 839 с.

Калашников А. Право сидящего // Рос. газета. 2019. 4 дек.

Качалов В. И. Теоретические основы доказывания при исполнении итоговых судебных решений в уголовном процессе России. М. : Юрлитинформ, 2017. 160 c.

Крьлиов А. А. Уголовно-процессуальная деятельность органов и учреждений уголовно-исполнительной системы России. М. : Проспект, 2017. 464 с.

Панасенко $E$. K. Латентность пенитенциарной преступности как угроза криминологической безопасности УИС // Закон и право. 2006. № 10. С. 61-63.

Хохрин C. A. Некоторые аспекты латентностной характеристики пенитенциарной преступности // Вестник Тверского гос. ун-та. Серия: Право. 2017. № 3. C. 61-74.

\section{References}

Antipov A. Yu. Use of evidence in criminal matters // in Sat. Organizational and legal support of the activities of institutions and organs of the FSIN of Russia: problems and development prospects in the context of reforming the peniten-

220 tiary system. Ryazan, 2015. P. 18-21.

Vaganov $A$. B. The criminological characteristics of penitentiary crime and its prevention : authoref. dis. ... Cand. jurid science Chelyabinsk, 2012. 30 p.

Gilin Ya. I., Acutaev R. M. Criminology. Theory, history, empirical base, social control. 2nd ed., revised and enlarged. St. Petersburg : Legal Center Press, 2009. 504 p.

Inshakov S. M. Theoretical foundations of research and analysis of latent crime. M. : Uniti-Dana, 2011. 839 p.

Kalashnikov A. The right of sitting // Russian newspaper. 2019. December 4.

Kachalov V. I. Theoretical foundations of proving in the execution of final court decisions in the Criminal Procedure of Russia. M. : Yurlitinform, 2017. $160 \mathrm{p}$. 
Krymov A. A. Criminal procedural activities of bodies and institutions of the Russian Penal System. M. : Prospekt, 2017. 464 p.

Panasenko E. K. The latency of the penitentiary crime as a threat to the criminological safety of the WIS // Right and Law. 2006. No. 10. P. 61-63.

Khokhrin S. A. Some aspects of the latent characteristics of penitentiary crime // Bulletin of Tver State University. Series: Right. 2017. № 3. P. 61-74.

\section{Академия ФСИН России}

Шаталов А. С., доктор юридических наук, проффессор кафбедры уголовного процесса и криминалистики

E-mail:asshatalov@rambler.ru

Акчурин А. В., кандидат юридических наук, доцент, начальник кафбедры уголовного процесса и криминалистики

E-mail:79206310258@yandex.ru
Academy of the Federal Penitentiary Service of Russia

Shatalov A. S., Doctor of Legal Sciences, Professor of the Criminal Process and Criminalistics Department

E-mail: asshatalov@rambler.ru

Akchurin A. V., Candidate of Legal Sciences, Associate Professor, Chief of the Criminal Process and Criminalistics Department

E-mail: 79206310258@yandex.ru 